be perfectly free from all disposition to form cancer. I say that is a strong case; it is a case, perhaps, that you would not meet with once in a hundred year's, but there it was as a fact. The argument I made use of with regard to the existence of cancer in females was not satisfactorily answered by Sir James Paget. Dr. Crisp, at the last meeting, said that I was wrong in my conclusions. I may be wrong, but I know this, that of the 500 cases recorded by Sir James Paget, 330 occurred in women, and there was no uterine case mentioned. Now, if you add the immense number of uterine cancers, which are certainly as frequent as breast cancers, the number will come to pretty nearly what I said. Sir James Paget says that it is because in the female this particular tissue is so liable to change. It is true that the breast tissue is liable to great variation; but although we frequently find a breast inactive in which cancer appears, how frequently do we find it occurring in an active breast. And even in the breast in which the cancer exists it is not in the whole breast, but only in a part of it. If the breast is a retrogressive organ, and you get cancer developed because it is retrogressive, why is it that you do not get cancer developed in the opposite breast when it occurs secondarily, when that opposite breast has been going on two or three years beyond the ordinary period, and is, therefore, in a state of greater retrogression? Surely we should expect to find, if the retrogression had much to do with the matter, that the second breast would be as frequently the seat of secondary affection as the first breast was of the primary. But we never find that. I think that is an answer to Sir William Jenner when he talks about the mode in which cancer is distributed in certain parts. You do not find it in parts where you would expect to have it, but you find it spread here and there at long distances in the lung or in the liver, or in the leg on the opposite side, or in any situation you please, except-where? Except in the situation in which you do find primary cancer almost invariably - that is, in the uterus or in the mamma. The mobility of cancer as being the source of secondary deposits $\mathrm{I}$ suppose is pretty generally admitted. Mr. Arnott's observations on that point, supported as they are by many members of the Society, I think, go to show that mobility alone will not account for them. What do we find in regard to the most mobile disease we have? The most mobile disease is melanotic sarcoma, a form of disease where you get a secondary outburst after the primary one over every part of the body, deposits taking place in dozens, twenties, or fifties. Monsieur Legouest, one of the best observers, has discovered that in that form of disease the corpuscles of the blood and the fluid of the blood contain dark-coloured pigment matter. Evidentiy the blood which is thus dispersed over the body is diseased blood. Now, I say you cannot argue from that that cancer is a blood disease. It is diseased blood just as syphilitic blood is diseased blood. Syphilitic blood is not primarily diseased blood unless it is born in the person. A person has syphilis; the blood becomes diseased, and if you inoculate it you will produce disease in anotber person, or get an outburst or something of that kind. It is not a growth; it is a deposit showing that there is malnutrition in some parts of the body-that is, a secondary condition dependent upon the primary inoculation. Here you get melanotic disease in the first instance before the secondary deposits take place. Examine the blood, and none is found. But if vou come to interfere with that, and you get this matter. carried into the system, you get it dispersed anywhere and everywhere. It grows by reproduction of the same disease as was originally inoculated in the blood-that is to say, it grows as melanotic sarcoma. If you compare that with true blood disease, with disease in which the blood becomes diseased by inoculation, what a wide difference there is. In the case of melanotic sarcoma, you get the melanotic sarcoma developed everywhere; in the case of syphilis, you get here a pustule and there an eruption over the body; you get a deposit of something here, and you get in another place an ulceration and a whole host of things not by any means like the primary disease that was inoculated, but a number of phenomena connected evidently with a diseased condition of the blood. In these cases of syphilis you may have, as Sir James Paget says, a total freedom from all disease for a long period. But the patient is not free from disease. For if offspring is begotten, the chances are that the child will be ill-developed. Something has been propagated that interferes with the nutrition of the offspring, and the offspring will be syphilitic. You do not find that in cancer. A question was asked the other day, as to whether, in the case of children of parents having cancer, there was anything analogous to what was found ix syphilis. Certainly not. I have seen many cases in whice the patient has died of cancer, and children have been bo:n while the cancer was progressing. I remember the case of a child whom I removed by the Cæsarean operation fron a woman who had cancer of the uterus. The child was born perfectly healthy, though the uterine cancer was going on around the very situation in which the child was deveioped. You do not find that in syphilis. If you have syphiis de. veloped in the body, there will be something in the srowth of the offspring indicating that the poison is there present. I must confess that the whole course of the argument has tended rather to confirm me in the view that originally cancer is a local affair, in the same sease that any peculiarity that we have in the body is local. It may be determined by some primary conditions of growth, but of that we understand no more than we understand the reason why bones are developed in certain forms, and why muscles are developed in certain forms. It is impossible to go into it. But there is a something in the tissue itself-I believe in the whole range of the tissues-it may be throughout the bones, or it may be throughout connective tissues, or it may be throughout any of the parts in which we have disease tending to develop primarily. If you have a cancerous mother you have cancer, not developed in the breast where it existed in the mother, but you may have it in any other part of the tissues in which a similar structure is present. A parent has a fatty tumour of the shoulder, and the offspring may have a fatty tumour in the arm or leg. But there is nothing in those persons that would necessitate the formation of cancer in some part or another. Suppose where there was an original tendency to cancer the breast was removed before the cancer was developed, I believo there is no special reason why cancer should develop at all. You do not know of the early existence of cancer in the uterus or the breast, because long before the persons themselves are aware of it the cancer has advanced, and disseminates itself throughout a wide range. I beg now to return my best thanks to the Society for the manner in which they have received this paper. The remarks that have been made respecting it will do what cancer itself doesthey will germinate (spermatically or in some other way) in the minds of those who have been paying attention to the subject. No doubt, as Sir Roger de Coverley says, "there is a great deal to be said on both sides," but I trust that the result will be that we shall arrive at some important trutbs in regard to this subject, and every truth that we do acquire will have its bearing sooner or later upon actual practice. I do not mean to say our views will lead us to a method of curing cancer, but we shall be led in the direction in which we can apply remedial agents, or, if not, we must fall back upon the only alternative left us, that of removing the disease as soon as possible af ter we have ascertained its presence.

The debate then terminated.

\section{THE FORTHCOMING ELECTION INTO THE COUNCIL OF THE ROYAL COLLEGE OF SURGEONS.}

To the Editor of 'I'HE LANCET.

Sin,-In reference to the forthcoming election into the Council of the Royal College of Surgeons, this statement is made in a contemporary:-_ Among the candidates spoken of are Mr. Savory, Mr. Baker of Birmingham, and Mr. Cooper Forster. Next to these in seniority stands Mr. Henry Smith, who has not yet, we believe, announced his intention."

Will you allow me to correct this error. I was elected a Fellow in December, 1849, whilst Mr. Savory and Mr. Baker were elected, each of them, in 1852. Mr. Cooper Forster is my senior by some few months.

I remain, Sir, your obedient servant,

Wimpole-street, W., April 22nd, 1874.

HenRy SMith. 